\title{
Cross-Reactive HIV-I Neutralizing Human Monoclonal Antibodies with Unique Features: Structural Mimicry of CD4, Conformational Flexibility, Lack of Light Chain Dimiter S Dimitrov**
}

Address: Protein Interactions Group, CCRNP, NCI-Frederick, NIH, Frederick, MD 21702, USA

Email: Dimiter S Dimitrov* - dimitrov@ncifcrf.gov

* Corresponding author ‡Presenting author

from 2005 International Meeting of The Institute of Human Virology Baltimore, USA, 29 August - 2 September 2005

Published: 8 December 2005

Retrovirology 2005, 2(Suppl I):S63 doi:10.1 I86/I742-4690-2-SI-S63

In the giant struggle with the long chronic HIV infection the immune system has generated unique antibodies matured to neutralize a virus which has evolved to escape them. I will describe unique features of a CD4bs (m18), and two CD4i (m12, X5) antibodies selected from immune phage libraries developed from long-term nonprogressors with high levels of broadly neutralizing antibodies. The $\mathrm{m} 18 \mathrm{H} 3$ shows striking similarity to the Ig CDR2-like $\mathrm{C}^{\prime} \mathrm{C}$ " region of the $\mathrm{CD} 4$ domain 1 which dominates the binding to gp120. The X5 H3 is exceptionally flexible - IgG X5 inhibits efficiently infections of cells with low surface concentrations of CCR5. M12 is the only HIV-specific antibody identified which does not express its light chain but still binds gp120 - it was engineered to a single domain antibody that neutralized isolates from different clades.

Mei-Yun Zhang, Vidita Choudhry, and Ponraj Prabakaran from my group, and our collaborators X. Ji, P. Kwong, C. Broder, G. Quinnan, R. Blumenthal, D. Montefiori, and their groups contributed to these results. 